\title{
Crítica do valor e dominação social em Moishe Postone: prolegômenos para repensar a crítica da economia política de Karl Marx
}

\begin{abstract}
Criticism of value and social domination in Moishe Postone: prolegomena to rethink Karl Marx's critique of political economy
\end{abstract}

\section{Gerson dos Santos Silva*}

\begin{abstract}
Resumo - Este artigo objetiva propor alguns elementos para se repensar a crítica da economia política de Marx frente à atual formatação do capitalismo. Nesse percurso, analisamos as contribuições de Moishe Postone em seu livro Tempo, trabalho e dominação social, de 1993, em conexão com os escritos maduros de Marx, reconstruindo a crítica das formas sociais capitalistas (mercadoria, valor, trabalho em seu duplo caráter, capital) e apontando a necessidade urgente de supressão histórica dessas categorias.

Palavras-chave: crítica da economia política; crítica do valor; dominação social.
\end{abstract}

\begin{abstract}
The objective of this article is to propose elements to rethink Marx's critique of political economy considering the current shape of capitalism. Along the way we analyzed the contributions of Moishe Postone in his book Time, Labor, and Social Domination (1993) in connection with the later writings of Marx, reconstructing the critique of capitalist social forms (commodity, value, work in its dual character, capital) and pointing the urgent need for historical suppression of these categories.
\end{abstract}

Keywords: critique of political economy; critique of value; social domination.

\footnotetext{
* Assistente Social pela Universidade Federal Fluminense (UFF), no campus de Rio das Ostras. Participante do Laboratório de Estudos em Teoria Social (LETS), coordenado pelo professor Ranieri Carli de Oliveira. Correspondência: Rua Recife, Lotes 1-7. Jardim Bela Vista, Rio das Ostras - RJ. CEP: 28895-532. Email: <gersonsantos.krisis@gmail.com>
} 


\section{Introdução}

Diante da atual encruzilhada histórica que vivemos, entendemos ser fundamental o esforço crítico de se pensar o nosso tempo e deixar contributos que venham nutrir e direcionar ações concretas comprometidas com a transformação radical dessa sociedade. Nesse sentido, nosso trabalho objetiva construir alguns elementos para se repensar a crítica da economia política de Marx frente à atual formatação do capitalismo. Deixamos aqui apenas algumas hipóteses de trabalho, algumas contribuições destituídas de qualquer traço de originalidade por parte deste autor que vos escreve.

A obra de Moishe Postone se inscreve no contexto da "crise do marxismo tradicional e da emergência do que parece ser uma nova fase do desenvolvimento do capitalismo industrial avançado" (POSTONE, 2014, p. 21). Sua abordagem se insere na corrente teórica chamada "crítica do valor" (wertkritik), que busca na crítica radical das categorias fundamentais da crítica de Marx as chaves para a apreensão das transformações societárias docapitalismo contemporâneo.

Na obra Tempo, trabalho e dominação social, Postone (2014) realiza uma reinterpretação da crítica da economia política de Marx buscando construir uma reconceituação da natureza da sociedade burguesa. Essa reinterpretação das categorias fundamentais da crítica imanente de Marx torna-se extremamente necessária, à medida que, a partir da reconceituação categorial, torna-se possível identificar a atualidade imprescindível da crítica da economia política frente à atual formatação do capitalismo e sua urgente necessidade de supressão histórica.

No percurso expositivo da obra, o autor apresenta críticas às debilidades das análises postuladas pelo chamado "marxismo tradicional"; essas limitações interpretativas se assentam na forma como as categorias básicas da crítica madura de Marx são analisadas. Dessa forma, o autor constrói uma série de argumentos críticos à luz dos escritos maduros de Marx, demonstrando um conjunto de problemas e lacunas dessas interpretações e as dificuldades de se pensar a superação do capitalismo a partir do "marxismo tradicional". Portanto, torna-se imprescindível explicitar a caracterização geral do que Postone (2014, p. 21-22) considera ser o "marxismo tradicional":

A expressão 'marxismo tradicional' não se refere a uma tendência histórica específica no marxismo, mas, de modo geral, a todas as abordagens teóricas que analisam o capitalismo do ponto de vista do trabalho e que caracterizam tal sociedade essencialmente em termos 
de relações de classe estruturadas pela propriedade privada dos meios de produção e uma economia regulada pelo mercado. As relações de dominação são entendidas primariamente em termos de dominação e exploração de classe. Como é sabido, Marx argumentou que no curso do desenvolvimento do capitalismo emerge uma tensão estrutural, ou contradição, entre as relações sociais que caracterizam o capitalismo e as forças produtivas. Em geral essa contradição tem sido interpretada como uma oposição entre, de um lado, propriedade privada e mercado e, de outro, o modo de produção industrial, pela qual a propriedade privada e o mercado são tratados como as marcas distintivas do capitalismo, e a produção industrial é postulada como a base de uma futura sociedade socialista.

O ponto nevrálgico que será tensionado por Postone (2014) relaciona-se à categoria trabalho e à perspectiva ontológica e trans-histórica abordada pelas análises tradicionais. Para o autor, o procedimento analítico do "marxismo tradicional", fundamentado na concepção de centralidade do trabalho, ancora-se em uma crítica que se reduz ao modo de distribuição e não ao modo de produção como tal, à medida que a possibilidade de uma nova forma histórica (socialismo) viria a se desenvolver na base do modo de produção industrial, pela mediação social do trabalho sobre uma estrutura igualitária de socialização de riquezas sociais. Esta concepção implica a supressão do capitalismo a partir do fim da propriedade privada dos meios de produção e do mercado como instância autorreguladora. Nesse sentido, esta crítica apresenta fragilidades que serão tensionadas à frente, pois, segundo a reinterpretação da crítica de Marx realizada por Postone, não se trata de realizar uma crítica à sociedade burguesa pelo ponto de vista do trabalho, mas sim partir do trabalho como ponto fundamental da crítica.

Para Postone (2014), a finalidade da crítica da economia política de Marx é propor uma exposição categorial que apreenda a especificidade da sociedade burguesa e, a partir disto, que oriente alternativas reais de sua negação histórica. Partindo desta compreensão de uma forma específica de dominação social presente na crítica de Marx, a negação histórica do capitalismo não se realizará no momento em que a classe trabalhadora tomar o poder, justamente pela compreensão de que a sociedade burguesa não se estrutura apenas em uma forma de dominação e exploração entre as classes. Sabemos que, de fato, as relações antagônicas entre as classes existem e se expressam via exploração; entretanto, essa característica constitui a sociabilidade imediata que ofusca a própria estrutura lógicohistórica do capitalismo, pois, na essência desta sociedade, a dominação é realizada como dominação social formal pela mediação do trabalho, constituindo relações nas quais os indivíduos são dominados pela produção, e não o contrário.

Para abordar as análises de Moishe Postone percorremos sua obra Tempo trabalho e dominação social, publicada originalmente em 1993 e 


\section{heVistg enl paltg}

\} CRÍTICA DO VALOR E DOMINAÇÃO SOCIAL EM MOISHE POSTONE - SILVA, G. S. \}

DOI: $10.12957 / R E P .2016 .25390$

traduzida para o português em 2014. No curso dessas análises, fundamentamos nossas leituras nos escritos maduros de Marx, recorrendo ao livro I de O capital (2013), ao Grundrisse (2011) e ao Contribuição à crítica da economia política (2008).

A partir de Postone (2014) podemos repensar a crítica de Marx ao capitalismo, apreendendo o caráter essencial da formação social capitalista, bem como seu desenvolvimento histórico, sua formatação especificamente reificada e suas formas particulares de dominação social abstrata. Essa compreensão implica pensar a sociedade burguesa para além das formas de aparência que a caracterizam. Por isso, Postone (2014, p. 18) não conceitua o capitalismo primariamente em termos de distribuição na esfera funcional do mercado e da propriedade privada dos meios de produção:

Conceituo o capitalismo em termos de uma forma historicamente específica de interdependência social com um caráter impessoal e aparentemente objetivo. Essa forma de interdependência se realiza por in-termédio de relações sociais constituídas por formas determinadas de prática social que, não obstante, se tornam quase independentes das pessoas en-gajadas nessas práticas.

Como veremos, esta característica do capitalismo de "interdependência social" implica o desenvolvimento de relações sociais que adquirem um caráter específico, pois são marcadas por uma "forma nova e crescentemente abstrata de dominação" (POSTONE, 2014, p. 18). À medida que essa forma de dominação social se externaliza e se autonomiza pela mediação social do trabalho na sociedade capitalista, seus imperativos e coerções impessoais passam a determinar transformações substantivas no conjunto da vida social, inviabilizando, assim, a possibilidade de relações sociais abertas entre os indivíduos e constituindo uma forma de relação ancorada na "dependência coisal". Nas palavras de Marx (2011, p. 112):

Essas relações externas tampouco são uma supressão das 'relações de dependência', dado que são apenas a sua resolução em uma forma universal; são, ao contrário, a elaboração do fundamento universal das relações pessoais de dependência. Também aqui os indivíduos só entram em relação entre si como indivíduos determinados. Essas relações de dependência coisal, por oposição às relações de dependência pessoal (a relação de dependência coisal nada mais é do que as relações sociais autônomas contrapostas a indivíduos aparentemente independentes, i.e., suas relações de produção recíprocas deles próprios autonomizadas), aparecem de maneira tal que os indivíduos são agora dominados por abstrações, ao passo que antes dependiam uns dos outros.

A forma de dominação abstrata da sociedade burguesa exige que as relações sociais ocorram como relações (reificadas) entre coisas; o produto final do trabalho tornou-se um bem externo, um corpo de valor que enfrenta 


\section{ApVistg all pgutg}

\} CRÍTICA DO VALOR E DOMINAÇÃO SOCIAL EM MOISHE POSTONE - SILVA, G. S. \}

DOI: $10.12957 /$ REP.2016.25390

seu próprio criador. Essa forma de "interdependência social" está diretamente ligada à especificidade histórica do trabalho na sociedade burguesa. O trabalho "constitui uma forma de mediação social historicamente específica, quase objetivo que, no âmbito da análise de Marx, serve como o fundamento social central das características essenciais da sociedade" (POSTONE, 2014, p. 19). Na forma como as relações sociais se estruturam no capitalismo, nenhum indivíduo consome diretamente o valor de uso que produz, mas é apenas pela mediação de seu próprio trabalho que ele consegue ter acesso aos produtos de que necessita. Ao inserir o trabalho e a mercadoria como mediações sociais únicas, o próprio trabalho e a mercadoria se relacionam, impedindo relações abertas entre os indivíduos. Trabalho, mercadoria e mercadoria-dinheiro tornam-se automediados, determinando que as relações sociais capitalistas ocorram impreterivelmente como relações entre coisas. Como veremos mais à frente, esta forma abstrata de dominação implica pensar a natureza da sociedade burguesa para além do conflito entre as classes sociais.

A natureza da sociedade burguesa é fundamentalmente marcada pelo trabalho em seu duplo caráter. Essa forma de mediação social constituída por um duplo caráter (abstrato-concreto) é histórica e particular da sociedade burguesa; desse modo, as formas de interação entre homem e natureza que precederam o capitalismo conservam particularidades que as difere da sociedade da mercadoria.

No curso expositivo de nossa análise, veremos que Postone (2014) realiza uma diferenciação entre o trabalho compreendido como categoria trans-histórica (fundamento ontológico do ser social) e o trabalho como mediação social especificamente capitalista (trabalho como substância social do capitalismo). A interpretação do trabalho realizada pelo "marxismo tradicional" compreende-o como atividade de transformação realizada em processos de interação entre o homem e a natureza, cuja finalidade é gerar um valor de uso que abarque suas necessidades. Em oposição direta a essa interpretação, o trabalho é apreendido como mediação social que possui caráter historicamente determinado, portanto, seu duplo caráter (dimensão concreta e abstrata) é o que constitui a especificidade das relações sociais da sociedade burguesa. Segundo Postone (2014, p. 19):

Na crítica madura de Marx, a noção de que o trabalho constitui o mundo social e é fonte de toda a riqueza não se refere à sociedade em geral, mas exclusivamente ao capitalismo, ou a sociedade moderna. Ademais, e isso é crucial, a análise de Marx não se refere ao trabalho como geral e trans-historicamente concebido - uma atividade finalística que medeia entre os seres humanos e a natureza, criando produtos específicos para satisfazer necessidades humanas especificas - mas a um papel peculiar desempenhado pelo trabalho somente na sociedade capitalista. 


\section{A crítica da economia política como crítica da dominação social capitalista}

Marx analisa a mercadoria como forma objetivada do trabalho na sociedade burguesa, de modo que a "substância social" que "aparece" na relação de troca entre mercadorias distintas é o próprio trabalho representado nessas mercadorias. Este trabalho, que foi despendido na produção de mercadorias, conserva duas dimensões: concreta e abstrata. A dimensão concreta, interligada ao processo de trabalho, realiza-se na relação entre os indivíduos e a natureza - relação na qual a matéria se transforma para que se crie um valor de uso. Essa dimensão concreta do trabalho não flutua no ar, pois se realiza contraposta historicamente pela dimensão abstrata do trabalho, como "trabalho não diferenciado". Nas palavras de Marx (2008, p. 54 - grifo nosso):

Para medir os valores de troca [expressões do valor] das mercadorias mediante o tempo de trabalho a elas incorporado, é necessário que os diferentes trabalhos sejam reduzidos a trabalho não diferenciado, uniforme, simples; em síntese: a trabalho que é idêntico pela qualidade e não se distingue senão pela quantidade. Essa redução apresenta a aparência de uma abstração; mas é uma abstração que ocorre todos os dias no processo de produção social. A conversão de todas as mercadorias em tempo de trabalho não supõe uma abstração maior, como tampouco é menos real que a [conversão] de todos os corpos orgânicos em ar. Na realidade, o trabalho que se assim se mede com o tempo não aparece como trabalho de distintos indivíduos; os diferentes indivíduos que trabalham surgem antes com simples órgão de trabalho.

Por isso, o trabalho no capitalismo se constitui como uma categoria distinta. Seu duplo caráter mostra que, de um lado, ele é um tipo particular de trabalho (concreto) que produz mercadorias específicas para terceiros (e não para seu produtor direto); por outro lado, é trabalho independentemente de seu conteúdo sensível (trabalho abstrato), pois serve ao produtor como meio pelo qual se adquire o produzido por outros trabalhadores. Nessa passagem, a categoria trabalho não aparece como simples "trabalho geral", o trabalho qualitativamente idêntico (substância) e quantitativamente variável (grandeza) adquire caráter socialmente válido à medida que assume "a forma do seu oposto imediato, a forma da generalidade abstrata" (MARX, 2008, p. 57), e se apresenta como uma abstração. Uma abstração que se faz real, visto que, em sua redução prática, constitui a forma específica de mediação social no capitalismo.

Partindo dessa perspectiva, Postone (2014) afirma que o trabalho na sociedade burguesa possui uma "dimensão social adicional". Essa "dimensão social" não é imanente a um conjunto de atividades intencionais que transformam a matéria pela mediação de instrumentos e técnicas, mas, como podemos ver: 
O trabalho constitui relações sociais no capitalismo. Mas o trabalho é uma atividade social objetivadora que medeia entre os humanos e a natureza. Então, é necessariamente como uma atividade objetivadora que o trabalho realiza no capitalismo a sua função como atividade socialmente mediadora. Portanto, o papel social específico do trabalho no capitalismo tem necessariamente de ser expresso em formas de aparência que são as objetivações do trabalho como atividade produtiva. Mas a dimensão social historicamente especifica do trabalho é ao mesmo tempo expressa e velada pela dimensão 'material' aparentemente trans-histórica do trabalho. (POSTONE, 2014, p. 194).

Valor, mercadoria e trabalho, por serem formas sociais que constituem um tipo específico de relação, precisam ser apreendidos como categorias que compõem uma forma de "interdependência social". A mercadoria (como forma geral do produto da sociedade burguesa), o valor (como forma geral de riqueza social) e o trabalho (como mediação social capitalista) caracterizam esse tipo específico de "interdependência social" uma vez que os indivíduos necessitam se submeter dia após dia ao ritual de compra e venda de mercadorias para sobreviverem. Nessa sociedade, os indivíduos não usufruem daquilo que produzem, mas vendem/compram mercadoria (força de trabalho) para adquirir mais mercadorias (dinheiro). O trabalho, em grande medida, é realizado como meio para se adquirir mercadorias. Para Marx (2013, p. 244 - grifo nosso), essa estranha forma de metabolismo social é especificamente capitalista:

Também as categorias econômicas que consideramos anteriormente trazem consigo as marcas da história. Na existência do produto como mercadoria estão presentes determinadas condições históricas e para se tornar mercadoria, o produto não pode ser produzido como meio imediato de subsistência para o próprio produtor. Se tivéssemos avançado em nossa investigação e posto a questão 'sob que circunstancias todos os produtos - ou apenas a maioria deles - assumem a forma da mercadoria?', teríamos descoberto que isso só ocorre sobre a base de um modo de produção especifico, o modo de produção capitalista.

Essa "forma de interdependência social" e de "dependência coisal" surge por meio de uma dinâmica histórica "lenta, espontânea e contingente" (POSTONE, 2014, p. 174). Quando trocamos mercadorias, estamos trocando unidades de puro dispêndio de força psicofísica cristalizada, ou seja, a repetição compulsória do ato de trocar (vender/comprar) unidades de trabalho (mercadorias) tornou-se um processo social estruturante da sociedade capitalista. Por isso, afirmamos que a mercadoria "aparece" como núcleo socializador no capitalismo, como "forma de aparência" de um tipo de dominação social específico.

Em uma sociedade determinada pela mediação reificada das mercadorias, as objetivações do trabalho de alguém são meios pelos quais se 


\section{heVistg enl paltg}

\} CRÍTICA DO VALOR E DOMINAÇÃO SOCIAL EM MOISHE POSTONE - SILVA, G. S. \}

DOI: $10.12957 / R E P .2016 .25390$

obtêm bens produzidos por outros; trabalha-se para adquirir outros produtos. Os produtos próprios servem a outra pessoa como um bem, um valor de uso, e servem ao produtor como um meio para obter produtos do trabalho de outros. Os trabalhadores possuem uma valiosa mercadoria, sua força de trabalho, uma mercadoria capaz de criar valor. Mediante isso, no momento histórico em que a força de trabalho se torna mercadoria e se instaura a propriedade privada dos meios de produção, os trabalhadores necessitam vender sua mercadoria (força de trabalho) para comprar outras. O processo de vender para comprar torna-se fulcral e, após seu desenvolvimento completo, penetrando todos os poros da vida social no capitalismo, ele alcançou um caráter necessário e sistemático. Assim, progressivamente, foi sendo destrutivo, rompendo as formas de relações abertas que caracterizavam as sociedades que precederam a forma histórica capitalista, instaurando-se de maneira global. Nas palavras de Postone (2014, p. 177):

Nas sociedades não capitalistas, as atividades de trabalho são sociais em virtude da matriz de todas de relações sociais abertas em que estão inseridas. Essa matriz é o princípio constituinte dessas sociedades; vários trabalhos ganham seu caráter social por meio dessas relações. Do ponto de vista da sociedade capitalista, relações em formações pré-capitalistas podem ser descritas como pessoais, abertamente sociais e qualitativamente particulares (diferenciadas de acordo com agrupamento e posição sociais e assim por diante). Consequentemente, atividades de trabalho são determinadas como abertamente sociais e qualitativamente particulares; vários trabalhos são imbuídos de significado pelas relações sociais que estão no seu contexto.

No capitalismo, o trabalho por si só constitui uma mediação social no lugar dessa matriz de relações. Isso quer dizer que as relações sociais abertas não conferem ao trabalho um caráter social; pelo contrário, uma vez que o trabalho medeia a si próprio, ele tanto constitui uma estrutura capaz de substituir os sistemas de relações sociais abertas quanto confere a si mesmo o seu caráter social. Esse momento reflexivo determina a natureza especifica do caráter social automediado do trabalho, bem como das relações sociais estruturadas por essa mediação social.

As relações qualitativamente particulares entre grupos e posições sociais (relações entre familiares, por exemplo) permanecem na forma histórica capitalista. No entanto, estas relações sociais se realizam determinadas pela estrutura impessoal de dependência coisal organizada e racionalizada pela mediação do trabalho. A categoria trabalho é uma generalidade abstrata, já que a dimensão abstrata do trabalho se encontra em estado latente de oposição à dimensão concreta do trabalho e, para poder realizar seu caráter social historicamente determinado, o trabalho precisa objetivar-se no horizonte concreto da sociedade.

Toda forma possui um suporte material; a forma de objetivação do trabalho é a mercadoria. Cada trabalhador, em sua exaustiva jornada 


\section{ApVistg all pgutg}

\} CRÍTICA DO VALOR E DOMINAÇÃO SOCIAL EM MOISHE POSTONE - SILVA, G. S. \}

DOI: $10.12957 /$ REP.2016.25390

de trabalho, produz valores de uso específicos (camisetas, granadas, calças jeans), porém, esses valores de uso desempenham o papel de mediação social. O devir de todas as mercadorias como mediação social é independente de sua aparência material. Como mediação social elas são apenas suportes (pouco importa se são camisetas ou bombas), ou seja, toda mercadoria é particular (valor de uso) e geral (valor).

Como atividade social mediadora, o trabalho é esvaído de sua particularidade concreta, tornando-se uma generalidade abstrata que, na figura do dinheiro, adquire um nível superior de autonomia. A generalidade abstrata do trabalho pode ser apreendida no próprio circuito lógico da mercadoria: vejamos que a determinação da forma sobre o conteúdo sensível se realiza pela forma do valor. A forma do valor encarnada na mercadoria encontra sua medida pelo critério temporal contido no conceito de "tempo de trabalho socialmente necessário". Nesse movimento próprio do mundo das mercadorias, uma determinada mercadoria posta em relações de troca com outras mercadorias perde seu caráter "singular relativo" e assume a estatura de mercadoria "equivalente total", metamorfoseando-se na forma dinheiro. Como dinheiro, a generalidade abstrata do trabalho adquire plena existência real; a forma valor já não depende do suporte material da imensa coleção de mercadorias.

Podemos encontrar, na crítica da economia política de Marx, uma crítica imanente da teoria do valor-trabalho da economia política clássica. Marx se apropria das categorias constitutivas desta teoria do valortrabalho e revela sua estrutura social histórica, na medida em que são categorias que não podem ser abarcadas como trans-historicamente constituidoras da riqueza de todas as sociedades. Pelo contrário, na crítica da economia política, Marx transforma essas categorias em "categorias críticas da especificidade das formas de riqueza e relações sociais no capitalismo" (POSTONE, 2014, p. 76). Portanto, na crítica de Marx, não se trata de uma reconceituação das categorias da teoria do valor-trabalho centrada na unicidade do trabalho como fonte de valor. Do mesmo modo, Marx não almeja revelar exclusivamente a exploração entre classes e a propriedade privada dos meios de produção. Para além dos mecanismos internos do mercado e da disposição de classes sociais antagônicas, vemos que, em Marx, podemos apreender a crítica da forma de riqueza específica do capitalismo (a crítica do valor, da mercadoria e do trabalho). O ponto referencial utilizado por Postone para reconstruir essa crítica transcorre na diferenciação entre valor e riqueza material. Por isso, numa reconceituação categorial adequada da crítica de Marx, Postone (2014, p. 148) afirma que:

Deve se concentrar na distinção feita por Marx entre valor e riqueza material; tem de mostrar que, na sua análise, valor não é essencialmente uma categoria de mercado, e que a 'lei do valor' não é simplesmente uma lei do equilíbrio econômico geral. 


\section{heVistg enl paltg}

\} CRÍTICA DO VALOR E DOMINAÇÃO SOCIAL EM MOISHE POSTONE - SILVA, G. S. \}

DOI: $10.12957 / R E P .2016 .25390$

O valor é a forma de riqueza específica da sociedade burguesa, uma forma social de riqueza constituída pelo puro dispêndio temporal de força psicofísica no processo de produção. Esse dispêndio é o fator imprescindível para a produção de riqueza das sociedades nas quais impera o modo de produção capitalista, pois a finalidade precípua da produção é gerar mais-valor. Quando analisamos o valor como categoria particular da sociedade burguesa, o trabalho que constitui essa sociedade aparece em dupla determinação (como trabalho abstrato-concreto). A partir dessa dupla natureza, como trabalho criador de valor, vemos que ele não pode ser apreendido meramente como atividade intencional que transforma a matéria natural em valor de uso. Neste sentido, se valor é uma categoria historicamente específica, o trabalho em seu duplo caráter também o é!

Na exposição de Marx (2013, p. 122), nas duas primeiras seções de $O$ capital, vemos que o movimento da categoria valor - como categoria fundamental da sociabilidade capitalista - constitui "um processo social que ocorre pelas costas dos produtores". Neste movimento de dominação impessoal do ser-valor, as suas diversas formas de manifestação disfarçam o que está na essência (o próprio valor), constituindo uma forma de sociabilidade especificamente capitalista. Esse tipo de sociabilidade é caracterizado por relações sociais que se diferenciam das formas de sociabilidade de outras sociedades que precederam o capitalismo, pois no lugar de relações sociais interpessoais abertas instaura-se:

Um conjunto quase independente de estruturas que se opõem aos indivíduos, uma esfera de necessidade impessoal 'coisal' e 'dependência coisal'. Consequentemente, a forma de dominação social característica do capitalismo não é abertamente social e pessoal. (POSTONE, 2014, p. 149).

Essa forma de dominação abstrata e impessoal se expressa na realidade como relações alienadas, em que as práticas sociais se realizam impondo aos indivíduos um comportamento atomístico e reificado. No interior destas práticas sociais inscritas no cotidiano, os indivíduos parecem independentes uns dos outros; as relações de trabalho, a inserção no mercado, o poder social do dinheiro constrói uma aparente relação de independência social quando, em verdade, os indivíduos são sujeitos "a um sistema de dominação social que não parece social, e sim objetivo" (POSTONE, 2014, p. 149). Nas palavras de Marx (2013, p. 167 - grifo nosso):

O comportamento meramente atomístico dos homens em seu processo social de produção e, com isso, a figura reificada de suas relações de produção, independentes de seu controle e de sua ação individual consciente, manifestam-se, de início, no fato de que os produtos de seu trabalho assumem universalmente a forma da mercadoria. 


\section{ApVistg all pgutg}

\} CRIITICA DO VALOR E DOMINAÇÃO SOCIAL EM MOISHE POSTONE - SILVA, G. S. \}

DOI: $10.12957 /$ REP.2016.25390

Nessa esteira, Postone (2014) retoma um conjunto de passagens da crítica de Marx para reconceituar a forma de dominação social particular do capitalismo. Para Marx, essa forma peculiar de dominação também pode ser caracterizada como a dominação dos indivíduos pela produção. "Os indivíduos estão subsumidos à produção social que existe fora deles como uma fatalidade; mas, a produção social não está subsumida aos indivíduos que a utilizam como seu poder comum" (MARX, 2011, p. 106107). Essa passagem nos permite afirmar que indivíduos subsumidos à produção são dominados pelo trabalho. A produção de mercadorias e o trabalho em seu duplo aspecto que nela se insere são formas de manifestação da estrutura impessoal e abstrata do capital.

Por isso, a dominação social da sociedade burguesa não pode ser adequadamente compreendida apenas como relação de dominação de uma classe sobre outra. A determinação primária dessa forma específica de dominação social capitalista reside na forma básica que estrutura a sociabilidade capitalista: o fato de os indivíduos serem compelidos à ininterrupta produção e troca de mercadorias para garantir sua sobrevivência. Vejamos:

No capitalismo, o trabalho social não é somente o objeto de dominação e exploração, mas é, ele próprio, o terreno de dominação. A forma não pessoal, abstrata, 'objetiva' de dominação característica do capitalismo está aparentemente relacionada à dominação dos indivíduos por seu trabalho social. Dominação abstrata, a forma de dominação que caracteriza o capitalismo, não pode ser simplesmente identificada com a operação do mercado; não se refere simplesmente à forma mediada pelo mercado em que se efetua a dominação de classe no capitalismo. Essa interpretação centrada no mercado admite que o terreno invariável de dominação social é a dominação de classe, e que o que varia é apenas a forma em que ela prevalece (diretamente ou via mercado). Essa interpretação é intimamente relacionada às posições que admitem que o 'trabalho' seja a fonte de riqueza e constitua trans-historicamente a sociedade, e que só examinam criticamente o modo com que se efetua a distribuição do 'trabalho' [...] embora o capitalismo seja, evidentemente, uma sociedade de classes, dominação de classe não é, de acordo com Marx, o terreno ultimo de dominação social nessa sociedade, mas se torna, ela própria, uma função de uma forma superior 'abstrata' de dominação. (POSTONE, 2014, p. 150).

A partir da perspectiva de reconceituar a natureza da sociedade capitalista e sua forma específica de dominação social, podemos repensar a condição de "sujeito histórico" postulada à "classe que vive do trabalho" pelo chamado "marxismo tradicional". No desenvolvimento da forma valor realizado por Marx, o valor como categoria automediada transforma-se em um "sujeito automático" (o capital). A relação tautológica do valor

${ }^{1}$ Categoria encontrada em Antunes (2003). 


\section{heVistg enl paltg}

\} CRÍTICA DO VALOR E DOMINAÇÃO SOCIAL EM MOISHE POSTONE - SILVA, G. S.\}

DOI: $10.12957 / R E P .2016 .25390$

consigo mesmo (relação de valorização do valor) constitui o "sujeito automático" do capital, um sujeito que, no curso de seu desenvolvimento, expressa formas de manifestação estruturantes que o disfarçam. Na medida em que este "sujeito automático" existe de modo historicamente determinado, podemos apreendê-lo como "sujeito histórico automático", como "contradição em processo" que atinge patamares de autonomização e lança seus imperativos no conjunto da vida social.

Partindo deste argumento, na estrutura das relações sociais capitalistas, a estrutura impessoal que faz com que os indivíduos sejam dominados por abstrações sociais se manifesta pela dominação social do trabalho, pois os indivíduos só se relacionam entre si pela troca de mercadorias, equiparando suas mercadorias e os trabalhos nelas representados. Essas relações são essencialmente determinadas por categorias próprias da sociedade burguesa, e não por grupos sociais demarcados por finalidades antagônicas:

A interpretação de Marx sobre o sujeito histórico com referência a categoria do capital indica uma mudança de uma teoria de relações sociais entendidas apenas em termos de classes sociais para uma teoria de formas de mediação social expressas por categorias como valor e capital [...] de acordo com Marx, esse sujeito não é um agente social concreto e humano, coletivo ou individual. Pelo contrário, o sujeito histórico analisado por Marx é composto por relações objetivadas, as formas categoriais subjetivo-objetivas características do capitalismo, cuja 'substancia' é o trabalho abstrato, ou seja, o caráter específico do trabalho como atividade socialmente mediadora no capitalismo. O sujeito de Marx, tal como o de Hegel, então, é abstrato e não pode ser identificado com nenhum ator social. Ademais, os dois se desenvolvem no tempo de uma forma que é independente da vontade individual. (POSTONE, 2014, p. 97).

Tendo em vista esta análise da natureza da sociedade burguesa e a condição de "sujeito histórico" do capital nela instaurada, o autor afirma que, em virtude de as interpretações do chamado "marxismo tradicional" não captarem esta particularidade, as formas de emancipação propostas se colocam apenas no nível da aparência. Por isso, a partir de suas interpretações, não alcançam uma análise adequada do capitalismo para a orientação de alternativas de sua superação radical.

\section{Repensar a crítica da economia política é realizar a crítica do valor e do trabalho na sociedade capitalista}

Marx, ao examinar a mercadoria, trata o valor de uso como suporte material que aparece determinado pela necessidade de materialidade da abstração valor. Junto deste valor de uso (riqueza material), a mercadoria 


\section{ApVistg all pgutg}

\} CRIITICA DO VALOR E DOMINAÇÃO SOCIAL EM MOISHE POSTONE - SILVA, G. S. \}

DOI: $10.12957 /$ REP.2016.25390

possui o valor de troca (forma de expressão da riqueza social abstrata especificamente capitalista). As mercadorias em relação de troca revelam uma substância em comum que as tornam passíveis de serem trocadas: o valor. Por isso, a relação de troca entre mercadorias é a relação entre uma determinação formal (o valor) e um suporte concreto (o valor de uso).

Como vimos, o valor de troca veio a lume como forma de expressão de um conteúdo diferente de si, o valor. Portanto, o valor de troca (aparência) é a forma como o valor (essência) aparece. O valor surge, então, como o "algo em comum" capaz de tornar todas as mercadorias mensuráveis, por isso a relação entre duas mercadorias é a relação direta entre uma determinação formal (o valor) e um suporte concreto (o valor de uso). Esta afirmação nos permite ampliar a compreensão sobre o trabalho na sociedade capitalista, de modo que a crítica da categoria valor torna-se, portanto, nosso ponto referencial.

Ao vislumbrarmos na vitrine de uma loja uma sedutora mercadoria, por exemplo, um vídeo game Xbox 360, não podemos ver ou tocar o valor desta mercadoria, podemos apenas nos deparar com sua materialidade útil e com a etiqueta de preços em sua fronte. A materialidade útil desta mercadoria e o preço fixado em sua testa são formas de expressão de algo imaterial (uma abstração que faz real), nos termos de Marx (2013): uma objetividade fantasmagórica. Portanto, sendo o valor algo oculto e intangível, sua manifestação se realiza pela mediação da esfera concreta do trabalho. Por outro prisma, do ponto de vista do valor (e do processo de valorização), a objetividade do valor se efetiva pela mediação essencial do trabalho abstrato, ou seja, a "substância formadora de valor" é o trabalho em sua forma de puro dispêndio de força psicofísica. É na relação entre abstrato e concreto que a objetividade do valor consegue se materializar como camisetas, bombas e calças jeans:

A objetividade do valor é diferente de Mistress Quickly, na medida em que não se sabe por onde agarrá-la. Exatamente ao contrário da objetividade sensível e crua dos corpos de mercadorias, na objetividade de seu valor não está contido um único átomo de matéria natural. Por isso, pode-se virar e revirar uma mercadoria como se queira, e ela permanece inapreensível como coisa de valor. Lembremo-nos, todavia, de que as mercadorias possuem objetividade de valor apenas na medida em que são expressões da mesma unidade social, do trabalho humano, pois sua objetividade de valor é puramente social e, por isso, é evidente que ela só pode se manifestar numa relação social entre mercadorias. Partimos do valor de troca das mercadorias ou da relação de troca das mercadorias para seguir as pegadas do valor que nelas se esconde. (MARX, 2013, p. 125).

O valor pode ser descrito como uma abstração formal, uma forma determinada socialmente que necessita do lastro material como seu suporte. $\mathrm{O}$ valor como riqueza social abstrata não pode ser mensurado pela quan- 


\section{heVistg enl paltg}

\} CRÍTICA DO VALOR E DOMINAÇÃO SOCIAL EM MOISHE POSTONE - SILVA, G. S. \}

DOI: $10.12957 / R E P .2016 .25390$

tidade concreta de trabalho (essa apenas Ihe serve de suporte), mas sim de quantidades temporais de trabalho abstrato. Não se trata de apreender o valor como uma redução abstrata apenas pensada, mas como uma abstração real, pois a universalidade formal do valor encontra o alicerce real para sua finalidade tautológica no horizonte material das sociedades onde impera o modo de produção capitalista.

Na categoria valor, podemos ter acesso ao que, antes, estava pressuposto por trás da relação de troca: a substância socialmente constituída, o trabalho reduzido a mero dispêndio de força psicofísica. A partir desta perspectiva podemos apreender que o valor é uma forma de riqueza estabelecida e regulada pelo tempo de trabalho socialmente necessário; quando se "cria" valor, as equivalências temporais do trabalho como mero dispêndio de força psicofísica são imprescindíveis, a despeito do valor de uso e da forma concreta com que esses trabalhos se realizam. Ainda que seja preciso uma hora para se fabricar uma granada ou 30 minutos para se produzir um casaco, o valor surge como cristalização de unidades de tempo de trabalho socialmente necessário. Por isso, quando se "cria" valor não se gera um conteúdo sensível, mas um corpo de valor, uma mediação social que exige que as relações sociais se realizem como relação entre coisas.

A mercadoria como núcleo socializador do capitalismo, forma estruturada e estruturante, reclama ser apreendida para além de sua característica de objeto destinado a realizar necessidades humanas. A mercadoria conserva em si a radiografia das relações sociais fundamentais que perfazem a sociedade burguesa, uma forma historicamente determinada de produto do trabalho (forma estruturada) que é o próprio princípio determinante da vida social (forma estruturante), pois carrega consigo o ser-valor. O valor, para além de uma "categoria de mercado", é a forma específica de riqueza da sociedade burguesa, bem como é a categoria que se expressa no horizonte desta sociedade, determinando a forma das relações de interdependência social fechada. Segundo Postone (2014, p. 63):

Embora exista a interdependência social, ela não é expressa abertamente na organização da sociedade, mas funciona indiretamente. O valor e a forma externa dessa interdependência não aberta, que expressa um modo indireto de distribuição social do trabalho e seus produtos.

A conexão social entre os indivíduos (indiferentes entre si) se realiza por uma dependência recíproca e multilateral, como forma de conexão social que confronta os indivíduos como simples meio para a finalidade impessoal de gerar o mais-valor:

Essa conexão social é expressa no valor de troca, e somente nele a atividade própria ou o produto de cada indivíduo devêm uma atividade ou produto para si; o indivíduo tem de produzir um produto universal 


\section{ApVistg all pgutg}

\} CRÍTICA DO VALOR E DOMINAÇÃO SOCIAL EM MOISHE POSTONE - SILVA, G. S. \}

DOI: $10.12957 /$ REP.2016.25390

- o valor de troca, ou este último por si isolado, individualizado, dinheiro [...] no valor de troca, a conexão social entre as pessoas é transformada em um comportamento social das coisas; o poder pessoal, em poder coisificado. (MARX, 2011, p. 105).

O dinheiro é a forma autonomizada do valor. Como desdobramento dialético das formas de valor, ele aparece como equivalente universal encarnado em uma determinada mercadoria, um ser-valor autônomo que não depende do suporte material da grande coleção de mercadorias para se expressar, visto que penetrou em um corpo capaz de espelhar o valor de troca de todas as mercadorias. Portanto, na forma dinheiro, o fetichismo se potencializa, pois encobre (em cédulas de papel, moedas e na virtualidade do crédito) o caráter social do trabalho, o puro dispêndio temporal de força psicofísica realizado em condições de exploração.

Na troca de mercadorias, o que se troca são unidades de trabalho cristalizado. Estas unidades representam valor e este valor se autonomiza na figura do dinheiro que tudo pode quantificar (roupas, bombas, horas de trabalho etc.). A mercadoria-dinheiro (ou o invólucro místico que tudo pode comprar) é a forma de manifestação do valor como categoria estruturante da vida social. No horizonte da experiência social capitalista, a abstração social do valor se impõe configurando um tipo específico de conexão social. Esta "conexão social" é analisada por Marx (2011) como prática social determinada por relações entre coisas; seu caráter impessoal e autônomo frente aos indivíduos faz com que tanto o trabalho quanto o seu produto apareçam como algo estranho e autônomo, dominando seu próprio criador (fetichismo da mercadoria).

O caráter social da atividade, assim como a forma social do produto e a participação do indivíduo na produção, aparece aqui diante dos indivíduos como algo estranho, como coisa; não como sua conduta recíproca, mas como sua subordinação a relações que existem independentemente deles e que nascem do entrechoque de indivíduos indiferentes entre si. A troca universal de atividades e produtos, que deveio condição vital para todo indivíduo singular, sua conexão recíproca, aparece para eles mesmos como algo estranho, autônomo, como uma coisa. (MARX, 2011, p. 105).

Seguindo as análises de Postone (2014), o valor surge como categoria central, pois, a partir da apreensão desta categoria, podemos adentrar os meandros da categoria trabalho, desvelando-a como especificamente capitalista. A partir da análise da categoria valor, percebemos que na mercadoria se conserva determinada quantidade de trabalho, no cerne da sociabilidade estruturada pelo valor este trabalho dispendido na produção das mercadorias adquire, simultaneamente, uma dimensão privada e social, como dois momentos de um mesmo trabalho. "O trabalho que se expressa como valor de troca é pressuposto como o trabalho do indivíduo isolado. 


\section{heVistg enl paltg}

\} CRÍTICA DO VALOR E DOMINAÇÃO SOCIAL EM MOISHE POSTONE - SILVA, G. S. \}

DOI: $10.12957 / R E P .2016 .25390$

Ele se torna social ao assumir a forma do seu oposto imediato, a forma da generalidade abstrata" (MARX, 2008, p. 57). Portanto, o trabalho em sua dupla determinação, objetivado na mercadoria, é o "trabalho do indivíduo isolado", um conjunto de atividades desempenhadas a partir de determinado recorte espaço-temporal de forma isolada, e assume a "forma de generalidade abstrata" ou "forma imediatamente social" (MARX, 2008, p. 57). Esta "forma imediatamente social" está no centro da sociedade burguesa. Vejamos:

Longe de tratar a oposição entre o social e o privado como a que existe entre o que e potencialmente não capitalista e o que e específico da sociedade capitalista, ele [Marx] trata a oposição em si, e seus dois termos, como peculiarmente característica do trabalho no capitalismo e da própria sociedade capitalista. Em outras palavras, a oposição entre o trabalho privado e o diretamente social e a de termos unilaterais que se complementam e dependem um do outro. Isso sugere que e precisamente o trabalho no capitalismo que tem dimensão diretamente social e que só existe numa estrutura social marcada também pela existência do 'trabalho privado'. (POSTONE, 2014, p. 66).

À medida que esta dimensão imediatamente social do trabalho torna-se central no horizonte dos processos sociais capitalistas, no interior destes processos sociais fetichistas desenvolve-se um tipo específico de dominação formal impositiva a partir de uma forma peculiar de riqueza (o valor) que sujeita os indivíduos de uma maneira objetiva e quase independente. Partindo disto, Postone retoma as análises de Marx sobre o trabalho à luz da categoria valor, e afirma que se torna imprescindível a apreensão deste caráter imediatamente social do trabalho na sociedade burguesa. Em síntese, o autor afirma que:

Na estrutura da teoria critica madura de Marx, o trabalho no capitalismo e diretamente social porque age como uma atividade de mediação social. Essa qualidade, que e historicamente única, distingue o trabalho no capitalismo do trabalho em outras sociedades e determina o caráter das relações sociais na formação capitalista. Longe de significar a ausência de mediação (ou seja, a existência de relações sociais não mediadas), o caráter diretamente social do trabalho constitui uma forma de mediação social especifica do capitalismo. (POSTONE, 2014, p. 67).

Em O capital, vemos que Marx (2013, p. 120-167), quando analisa a relação de confronto entre mercadorias, refere-se ao trabalho nelas representado como "trabalhos privados, separados e mutuamente independentes uns dos outros". Nesta relação, os indivíduos desempenham um comportamento particular: "o comportamento meramente atomístico dos homens em seu processo social de produção" é esta particularidade. Nesse sentido, a crítica que Marx desfere não deve ser apreendida como mera 


\title{
ApVistg all pgutg
}

\} CRÍTICA DO VALOR E DOMINAÇÃO SOCIAL EM MOISHE POSTONE - SILVA, G. S. \}

DOI: $10.12957 /$ REP.2016.25390

crítica de um modo atomizado de experiência social, em que a esfera do trabalho se reduz às relações entre indivíduos separados no tempo e no espaço, desempenhando atividades laborais. Para além disso:

\begin{abstract}
[A crítica de Marx] analisa a sociedade capitalista em termos de uma oposição entre os indivíduos isolados e a coletividade social. A crítica se aplica aos dois termos; ela afirma que eles são estruturalmente relacionados e que formam uma oposição especifica do capitalismo. A análise crítica de Marx dessa oposição é desenvolvida do ponto de vista da possibilidade histórica da sua superação, representado pela noção marxiana do indivíduo social. Pela mesma razão, vemos agora que a crítica marxiana do trabalho no capitalismo não e uma crítica do caráter privado do trabalho sob o ponto de vista do trabalho diretamente social; pelo contrário, é uma crítica do trabalho privado e do trabalho imediatamente social como complementares, como termos unilaterais de uma oposição elementar que caracteriza a sociedade capitalista. (POSTONE, 2014, p. 67).
\end{abstract}

Nesta perspectiva, apreendendo a categoria valor a partir da crítica de Marx, ou seja, para além de uma categoria encerrada no mercado, o caráter privado e social do trabalho aparece em "oposição recíproca". A crítica de Marx, assim, direciona-se à natureza da mediação social que constitui a formação social capitalista, tendo em vista que o que fundamenta essa formação social é a dimensão específica de sua mediação social (o trabalho em seu duplo caráter). Ou seja, "a análise de Marx é uma crítica das relações sociais mediadas pelo trabalho sob o ponto de vista da possibilidade historicamente emergente de outras mediações sociais e políticas" (POSTONE, 2014, p. 67). Por fim, a principal característica da sociedade burguesa se concentra na formatação específica de suas relações e mediações sociais, relações e mediações que se desenvolvem a partir de um tipo específico de trabalho, por ser nesta sociedade que esse tipo de trabalho atinge uma dimensão social única.

Em nossas análises, o valor apareceu como categoria central, uma categoria que apresenta uma dupla determinação; ao mesmo tempo em que é forma abstrata de riqueza da sociedade burguesa, também é forma de relação social que extrapola os limites do mercado, perpassando unilateralmente todas as esferas da vida social.

Como forma de riqueza abstrata, o valor se realiza como quantidade temporal de trabalho. A "mercadoria especial" do capitalismo capaz de formar valor se expressa no fato de grupos sociais se separarem no espaço e no tempo, inserindo-se em fatigantes jornadas de trabalho. Nesse sentido, a dimensão de temporalidade do valor como riqueza abstrata encontra seu suporte na forma de relações sociais concretas mediadas essencialmente pelo trabalho.

No tecido social, essas relações expressam seu fundamento em atos (ininterruptamente repetidos) de compra e venda de mercadorias. O 


\section{heVistg enl paltg}

\} CRÍTICA DO VALOR E DOMINAÇÃO SOCIAL EM MOISHE POSTONE - SILVA, G. S. \}

DOI: $10.12957 / R E P .2016 .25390$

trabalho como mediação social passa de meio a fim em si próprio, bem como a finalidade central de transformar a mercadoria em dinheiro constitui a "mudança de forma" estruturante da sociedade burguesa; "de simples meio do metabolismo essa mudança de forma converte-se em fim de si mesma" (MARX, 2013, p. 204). Por isso, a categoria que adquire centralidade no capitalismo é o valor, o valor é a essência de um modo de produção cujo "pressuposto é e continua sendo a massa do tempo de trabalho imediato, o quantum de trabalho empregado como o fator decisivo da produção de riqueza" (MARX, 2011, p. 587).

O desenvolvimento da chamada "grande indústria" viabilizou o crescimento exponencial da produtividade. O curso desse desenvolvimento é caracterizado por uma progressiva aplicação tecnocientífica na produção de riqueza material. Nesse sentido, o progressivo aumento do capital constante e a redução do capital variável destituiu, em certa medida, o lugar central do tempo de trabalho humano na produção. Para Marx (2011, p. 587):

À medida que a grande indústria se desenvolve, a criação da riqueza efetiva passa a depender menos do tempo de trabalho e do quantum de trabalho empregado que do poder dos agentes postos em movimento durante o tempo de trabalho, poder que - sua poderosa efetividade -, por sua vez, não tem nenhuma relação com o tempo de trabalho imediato que custa sua produção, mas que depende, ao contrário, do nível geral da ciência e do progresso da tecnologia, ou da aplicação dessa ciência à produção. (Por seu lado, o próprio desenvolvimento dessa ciência, especialmente da ciência natural e, com esta, todas as demais, está relacionado ao desenvolvimento da produção material.) A agricultura, p. ex., torna-se simples aplicação da ciência do metabolismo material, de forma a regulá-lo do modo mais vantajoso possível para todo o corpo social. A riqueza efetiva se manifesta antes - e isso o revela a grande indústria - na tremenda desproporção entre o tempo de trabalho empregado e seu produto, bem como na desproporção qualitativa entre o trabalho reduzido à pura abstração e o poder do processo de produção que ele supervisiona.

A partir desta perspectiva, podemos afirmar que essa diferença entre riqueza material e valor expressa a contradição interna do capital seu limite lógico-histórico - como uma oposição aguda entre uma riqueza abstrata especificamente capitalista (valor), formada por massas de tempo de trabalho imediato, e uma riqueza material que dispensa o mesmo critério abstrato impessoal. No curso da ampliação tecnocientífica do capitalismo, as mercadorias passam a ser produzidas com menor participação do trabalho humano. Com o desenvolvimento tecnocientífico, o valor se torna progressivamente menos adequado como medida de riqueza. O que está posto é a relação conflitante entre uma forma de riqueza alicerçada em medidas de tempo de trabalho humano frente ao inestimável potencial de produção 


\section{ReVistg all paltg}

\} CRÍTICA DO VALOR E DOMINAÇÃO SOCIAL EM MOISHE POSTONE - SILVA, G. S.\}

DOI: $10.12957 /$ REP.2016.25390

de riquezas presente no capitalismo contemporâneo, fazendo com que o trabalho, em alguma medida, se torne redundante.

Este caráter redundante do trabalho pode ser apreendido ao pensarmos o amplo desenvolvimento tecnocientífico do capitalismo a partir da Terceira Revolução Industrial: o desenvolvimento da informática, robótica e a participação de impressoras 3D no lugar de trabalhadores. Com isso, o trabalho atinge a condição de redundante (ou, para Postone, "supérfluo"). Segundo Marx (2011, p. 588):

O trabalho não aparece mais tão envolvido no processo de produção quando o ser humano se relaciona ao processo de produção muito mais como supervisor e regulador. (O que vale para a maquinaria, vale igualmente para a combinação da atividade humana e para o desenvolvimento do intercâmbio humano). Não é mais o trabalhador que interpõe um objeto natural modificado como elo mediador entre o objeto e si mesmo; ao contrário, ele interpõe o processo natural, que ele converte em um processo industrial, como meio entre ele e a natureza inorgânica, da qual se assenhora.

O valor, dada a amplitude da composição orgânica do capital, torna-se progressivamente obsoleto, pois a sua vitalidade social reside na própria determinação abstrata de riqueza que ele exige - mesmo diante do desenvolvimento tecnocientífico, no qual a riqueza material depende cada vez menos de tempo de trabalho. $\mathrm{O}$ valor sem essa determinação essencial historicamente assentada se tornaria obsoleto, portanto, extinto.

A contradição básica no capitalismo, vista dessa forma, é baseada no fato de que a forma de relações sociais e riqueza, bem como a forma concreta do modo de produção, continuam determinadas pelo valor, mesmo quando se tornam anacrônicas do ponto de vista do potencial de criação de riqueza material do sistema. Em outras palavras, a ordem social mediada pela forma-mercadoria gera, de um lado, a possibilidade histórica de sua própria negação determinada - uma forma diferente de mediação social, outra forma de riqueza e um novo modo de produção não mais baseado no trabalho humano direto fragmentado como parte integral do processo de produção.

Frente ao inestimável potencial produtivo do capitalismo contemporâneo, o valor torna-se, em alguma medida, anacrônico, e tal caráter advém exatamente de seu impulso tautológico de autovalorização. Portanto, superar o capitalismo implica a direta abolição do valor como forma social de riqueza. Esta abolição não está relacionada diretamente com a distribuição de riqueza, mas está intrinsecamente relacionada com o fim da forma social ancorada no valor. Abolir a isso exige o fim do tempo de trabalho como medida social de riqueza. Postone (2014, p. 44) afirma que:

Portanto, a superação do capitalismo, como apresentada nos Grundrisse, envolve implicitamente a superação dos aspectos formais e 
materiais do modo de produção firmado no trabalho assalariado. Ela deverá resultar na abolição de um sistema de distribuição baseado na troca da forca de trabalho, como uma mercadoria, por um salário, com o qual se adquirem os meios de consumo; ela também deverá resultar na abolição de um sistema de produção baseado no trabalho proletário, ou seja, na característica unilateral e fragmentada da produção industrial capitalista. Em outras palavras, a superação do capitalismo envolve também a superação do trabalho concreto executado pelo proletariado.

Seguindo as trilhas de Postone, podemos concluir que uma transformação societária radical que venha a abolir o capitalismo demanda a apreensão desta natureza essencial da sociedade burguesa. Construir alternativas verdadeiramente emancipatórias implica o reconhecimento do valor como categoria central estruturada e estruturante de relações sociais historicamente determinadas; por isso (e vice-versa), abolir o capitalismo é abolir o valor!

Assim, em nossa perspectiva, repensar a crítica de Marx significa retomar o projeto da crítica da economia política e reinterpretá-lo, não por mero exercício exegético dos textos maduros deste autor, mas pela análise da crítica das formas sociais do capitalismo nos textos marxianos, em articulação direta com as transformações societárias que conformam a atual formatação do capitalismo. Esta articulação direta entre a crítica e os desdobramentos reais do capitalismo não pode se encerrar em uma crítica à exploração entre classes ou uma crítica ao neoliberalismo ${ }^{2}$, como temos visto nos círculos hegemônicos da esquerda.

Conforme já destacado, o chamado "marxismo tradicional" interpreta a sociedade burguesa pela "crítica do ponto de vista do trabalho", ou seja, como uma sociedade regulada pelo mercado e caracterizada por classes sociais antagônicas que se estruturam na propriedade privada dos meios de produção. Segundo essa leitura, instaura-se uma contradição latente e expansiva entre a produção industrial e as relações sociais de produção postas. Partindo disso, avalia-se que, em consequência do desenfreado processo de reprodução ampliada de capital e suas crises imanentes, o capitalismo se tornaria anacrônico, ou seja, o modo de distribuição da riqueza social fundado na propriedade privada dos meios de produção e no mercado como regulador social viria a se tornar cada vez mais inadequado frente à produção industrial madura do capitalismo.

A partir deste panorama, os postulados do marxismo tradicional afirmam que, dada a contradição latente entre as relações sociais capitalistas e as forças de produção, o desenvolvimento histórico do capitalismo o tor-

\footnotetext{
${ }^{2}$ Em nossa abordagem, o neoliberalismo seria a forma de manifestação histórica e política de uma sociedade estruturada por abstrações sociais (mercadoria, valor, trabalho abstrato-concreto, dinheiro e capital) que deflagram um tipo específico de dominação social impessoal. Dentro dos limites deste trabalho, uma análise aprofundada do neoliberalismo não se faz possível, pois não se insere como nosso objeto.
} 


\section{ApVistg all pgutg}

\} CRÍTICA DO VALOR E DOMINAÇÃO SOCIAL EM MOISHE POSTONE - SILVA, G. S. \}

DOI: $10.12957 /$ REP.2016.25390

naria obsoleto, suas relações sociais haveriam de ser suplantadas. O papel do desenvolvimento histórico do capitalismo seria o de preparar o terreno para a emergência de outra forma de relação social, tendo em vista que as pré-condições sociais já estariam postas e, portanto, bastaria detonar a propriedade privada dos meios de produção, abolir as classes sociais e estabelecer um planejamento econômico centrado na distribuição equânime das riquezas sociais entre os indivíduos. Retomando a perspectiva da reconceituação crítica de Marx, Postone (2014, p. 23) afirma que:

Se as forças produtivas (que, de acordo com Marx, entram em contradição com as relações capitalistas de produção) se identificam com o modo industrial de produção, então esse modo e implicitamente visto como um processo puramente técnico, intrinsecamente independente do capitalismo, que e tratado como um conjunto de fatores extrínsecos agindo sobre o processo de produção: propriedade privada e condições exógenas da valorização do capital numa economia de mercado. A dominação social no capitalismo e percebida essencialmente como dominação de classe, que continua externa ao processo de produção. Essa analise implica que a produção industrial, uma vez historicamente constituída, e independente do capitalismo, e não intrinsecamente ligada a ele. A contradição marxiana entre forças e relações de produção, quando entendida como uma tensão estrutural entre, de um lado, produção industrial e, de outro, propriedade privada e mercado, e percebida como uma contradição entre o modo de produção e o de distribuição. Portanto, a transição do capitalismo para o socialismo e vista como uma transformação do modo de distribuição (propriedade privada e mercado), mas não do de produção. Pelo contrário, o desenvolvimento da produção industrial em grande escala e tratado como a mediação histórica que liga o modo capitalista de distribuição a possibilidade de outra organização social de distribuição. Mas, uma vez desenvolvido, o modo industrial de produção baseado no trabalho proletário e considerado historicamente final.

A partir disso podemos concluir que - se a supressão da sociedade burguesa se realizar pelo modo de distribuição, e o desenvolvimento da produção industrial em grande medida permanecer como fundamento para outra forma histórica - a crítica do ponto de vista do trabalho não nos permite pensar o próprio modo de produzir, tendo em vista que essa nova forma histórica (socialismo) se expressaria apenas como um novo aporte administrativo e político-econômico da forma industrial de produção gerada no capitalismo. O socialismo seria uma "forma social de distribuição" adequada à produção industrial; o modo de produção não é criticado radicalmente, pelo contrário, ele é o ponto referencial para a construção da crítica.

Indubitavelmente, a exploração entre classes, legitimada pelo Estado e garantida na propriedade privada dos meios de produção, está pre- 


\section{ReVista ell pautg}

\} CRÍTICA DO VALOR E DOMINAÇÃO SOCIAL EM MOISHE POSTONE - SILVA, G. S. \}

DOI: $10.12957 / R E P .2016 .25390$

sente nesta sociedade, desencadeando efeitos devastadores. A questão que se coloca, entretanto, como grande desafio para um projeto de crítica radical é a ultrapassagem da epiderme social para alcançarmos a medula essencial dessa sociedade. Sem uma crítica radical do valor não atingimos esse intento.

\section{Considerações finais}

Nosso trabalho objetivou construir alguns singelos aportes para ampliar as possibilidades de se repensar a crítica da economia política de Marx. Diante da extensão e complexidade presente na interlocução entre as análises de Moishe Postone e os escritos maduros de Marx, deixamos apenas algumas sinalizações conclusivas que abarquem pretensões críticas direcionadas à construção de alternativas concretas de transformação societária radical.

Reconhecendo os limites deste artigo, reiteramos que aqui encontram-se materializados apenas alguns singelos aportes que visam nutrir hipóteses de trabalho, hipóteses comprometidas com o esforço crítico de pensar este "novo tempo do mundo" e as alternativas possíveis de sua supressão histórica. 


\section{heVista dill pautg}

\} CRÍTICA DO VALOR E DOMINAÇÃO SOCIAL EM MOISHE POSTONE - SILVA, G. S. \}

DOI: $10.12957 /$ REP.2016.25390

\section{Referências}

ANTUNES, R. Os sentidos do trabalho: ensaio sobre a afirmação e negação do trabalho. São Paulo: Boitempo. 2003.

MARX, K. Contribuição à crítica da economia política. São Paulo: Expressão Popular. 2008

. Grundrisse. São Paulo: Boitempo. 2011.

2013.

. O capital - crítica da economia política. São Paulo: Boitempo.

POSTONE, M. Tempo, trabalho e dominação social. São Paulo: Boitempo. 2014.

Recebido em 11 de abril de 2016.

Aprovado para publicação em 25 de maio de 2016.

DOI: $10.12957 /$ rep.2016.25390

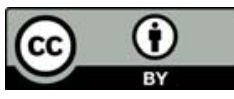

A Revista Em Pauta: Teoria Social e Realidade Contemporânea está licenciada com uma Licença Creative Commons Atribuição 4.0 Internacional. 